\title{
LA EXPERIENCIA DE LOS NOVELISTAS
}

JOSÉ MIGUEL OVIEDO: Vamos a comenzar nuestra última sesión con los novelistas invitados: Carlos Fuentes, Juan Goytisolo, Mario Vargas Llosa y Jorge Edwards. El tema de esta mesa es muy amplio, según indica el título: "La novela en español, hoy: la experiencia del escritor". La idea es muy simple; es la de provocar un diálogo, la de intentar un ejercicio de afinidades y contrastes entre la experiencia artística y humana del escritor a uno y otro lado del Atlántico. No hemos querido plantearla en un plano teórico, ni que ellos hagan una especie de resumen o conclusión de lo hasta aquí expuesto, sino que, en un plano muy concreto, testimonial, y personal, nos expliquen qué es lo que significa escribir novelas en esta lengua, en España o en Hispanoamérica. Para tratar de precisar un poco más el diálogo, voy a sugerir, meramente sugerir, algunas perspectivas a los novelistas aquí presentes como punto de partida para el diálogo. Carlos Fuentes, como todos saben, ha dedicado un libro y una larga devoción a Cervantes y ése podría ser quizá un buen motivo para su intervención hoy día, puesto que ayer en alguna ponencia se habló de la relación entre Terra Nostra y el libro de Fuentes sobre Cervantes. Y también quizás le interese hablar a Carlos sobre la España, una España más imaginaria que histórica subraya él, que aparece en Terra Nostra. Jorge Ed wards ha vivido largos años en España, especialmente en Barcelona, y es un testigo privilegiado y un activo protagonista de la vida intelectual catalana, sobre la cual nos puede decir mucho en la época de Franco y la que le sigue. Mario Vargas Llosa comparte una experiencia barcelonesa semejante a la de Jorge, y algo más, una pasión sumamente divulgada por la novela pre-cervantina, la novela de caballerías, que es un tema que quizá le guste a él tratar ahora. Y Goytisolo es un caso muy especial porque en el libro de Fuentes titulado La nueva novela hispanoamericana, hay un estudio sobre Goytisolo. No es una errata, no es un accidente: Fuentes decidió considerar a Goytisolo como un hispanoamericano. Y éste es un tema que tal vez le interese esclarecer o no a Juan. Sin embargo, Juan me ha dicho, antes de subir a esta mesa, que él preferiría comenzar haciendo algo que escapa en cierto sentido a los marcos del título que lleva esta mesa, pues intenta ser una respuesta a los comentarios que en una mesa se le hizo a sus novelas--una crítica a la crítica, a los papers presentados por los profesores Sobejano, Levine y Bieder. Así es que en un intento de agudizar las contradicciones y de provocar más diálogo, yo quisiera comenzar dándole la palabra a Juan. 
JUAN GOYTISOLO: No se trata de una respuesta sino simplemente de una iiıpresión como autor acerca de la discusión de esta mesa redonda. Se trata de un texto muy breve. Cuando me preguntaron mi opinión, porque se discutía de diferentes interpretaciones de lo que yo había escrito, dije que prefería reservarme, que haría una pequeña nota, y es lo que he hecho esta noche. En una secuencia de mi novela Makbara, un troglodita rescatado de las alcantarillas de una gran ciudad norteamericana asiste, grotesco y estupefacto, a un coloquio interdisciplinario de autoridades universitarias en las que éstas intentan aclarar la presencia y significado de dicho sujeto en tan nauseabundos parajes con gran acopio de ciencia, saber, imaginación, cultura, rigor e inventiva. El cuerpo del delito, el imposible cavernícola, concurre abrumado a su brillante despliegue teórico, estrujando amorosamente entre las manos un arrugado klínex.

Les confesaré que a lo largo de estas interesantes jornadas--concretamente en las que se han dedicado a mis trabajos, imagino que una experiencia parecida será la de Carlos Fuentes y Mario Vargas Llosa--no he dejado de identificarme un solo instante con el cuitado personaje. Con admiración, con maravilla, casi con pasmo, he escuchado las diversas ponencias consagradas a un cuerpo textual-mi obra--en las que la ciencia, saber, imaginación, cultura, rigor, inventiva de los autores merecían, sin duda, el aplauso. La organización del simposio, ponencias, discusiones, en las que yo--o por mejor decir, un doble mío-intervenía con el mismo despego con que trataría un tema ajeno y remoto, son dignos de todo encomio. El acto habría resultado absolutamente perfecto si no hubiese sido por el hecho de que en él sobraba alguien, y este alguien superfluo, incómodo, molesto, y embarazoso era y es, como habrán adivinado ustedes, su modesto y seguro servidor.

¿Cómo establecer en efecto un nexo entre mi presencia grotesca y estupefacta y los análisis y radiografías de mi cuerpo textual? El espacio moral, la distancia íntima, me parecían insalvables. ¿Cómo formular ante ustedes, por ejemplo, los "bueno, yo, en realidad lo que había querido decir era que...", si el corpus escrito había escapado definitivamente de mis manos, si las intervenciones y ponencias ajenas lo aclaraban con nitidez excepcional? ¿Cómo desmentir con mis balbuceos y gruñidos, discursos coherentes y razonables, máxime si se tiene en cuenta que sus autores son amigos y colegas míos y que, por contera, admiro sinceramente su trabajo? La amistad, la decencia, el respeto debido al respetable, eran otros tantos argumentos de peso que inducían a un servidor a callarse. Por una cuestión de dignidad y deferencia por organizadores, ponentes, y públicos, tendría que haber hecho mutis de modo irrevocable y absoluto, esto es, debería haberme muerto. 
Muerto y sólo muerto, desembarazándolos a ustedes del cuerpo del delito, hubiera podido conferir al acto cultural que celebramos toda su profundidad y alcance. Las teorías, doctrinas, discursos, hipótesis, habrían podido desplegarse entonces con sereno, natural esplendor, sin interferencia física alguna, sin temor de ser contradecidos por el cuerpo innecesario y culpable. Pero, paciencia: si, como decía justamente Cernuda, "el mayor defecto de un poeta es estar vivo", éste es un defecto que el tiempo se encarga generosamente de subsanar.

Mi pequeña experiencia de bricoleur crítico-mis calas en la obra de autores tan dispares como Rojas, Quevedo, o Blanco White-me han enseñado no obstante que dichos escritores eran meros, sucesivos pretextos para mi propio y obsesivo discurso; que, hablando de ellos, no cesaba un instante de hablar de mí. Al releer mis ensayos y artículos, imaginamos su sorpresa, confusión, quizás su cólera contenida, ante la reconstrucción peculiar, elaborada, con fragmentos y materiales dispersos, extraídos de sus escritos. ¿Por qué ciertos ladrillos o piedras y no otros? ¿Qué hubiera dicho Cervantes en una asamblea de cervantistas, Galdós en un simposio de galdosianos, Martín Santos a un congreso de martínsantistas?

Sin pretender compararme ni un instante a estos grandes o pequeños maestros, quiero acabar esta breve y excusable intervención formulando estas preguntas. No me cabe ninguna duda de que ustedes tienen razón y de que únicamente mi presencia es engorrosa e inútil. Dentro de equis años-los que me otorgue Dios o Allah - todo saldrá con seguridad, señoras y señores, mucho más lucido.

CARLOS FUENTES: $\boldsymbol{A}$ hard act to follow. . Yo, al contrario de Juan no estuve presente en ninguna sesión en la que se habló de algo tan remoto como un escrit or lla mado Fuentes o los libros que ha escrito, que están muy lejos de mí, hoy, aquí. Pero yo acepto todo, lo respeto todo, y lo agradezco todo, convencido como estoy de que la crítica literaria es una rama de la literatura fantástica. La otra rama, como lo ha dicho Borges, es la metafísica, por supuesto. Y después de oír a Juan, me convenzo en realidad que no debemos hablar de nuestros libros. Yo estoy, con respecto a Terra Nostra, más que satisfecho, más que recompensado por lo que han escrito, precisamente José Miguel Oviedo o Juan Goytisolo, o por lo que han dicho esta mañana Paul West y William Gass. Estuve tentado en un momento, cuando José Miguel me invitó a hablar sobre España y Terra Nostra a hablarles de una experiencia que sería, sin embargo, demasiado larga. Yo estoy convencido de que no salí de España en Terra Nostra sino que llegué a España. Y en realidad mi Puerto de Palos, por así decirlo, fue mi vida personal, mis obsesiones, una experiencia que tuve con los brujos del estado de Oaxaca en México, con la silosibín. Yo 
no sabía esto bien hasta el año pasado en que me hice psicoanalizar en París por un amigo mío que se llama Mark Nacht, que es uno de los pilares de la escuela de París, de Lacan. Entonces, entendimos, creo, desde un punto de vista psicoanalítico, qué era Terra Nostra, cómo se fundía con las dos obsesiones básicas que recorren toda mi obra, que son el mied o y la identidad, el terror y la identidad. Y cómo Terra Nostra es simplemente una dialéctica de lo accesible y de lo inaccesible, el hoyo, del deseo de penetrar el hoyo y del miedo de ser expulsado a través del hoyo, lo cual tiene que ver con el sexo, el oro, el excremento, Don Juan, la muerte; con el hecho monstruoso, supremo, de nacer de un cadáver, que quizás es como España aparece en Terra Nostra.

Pero no quiero, digo, hablar de estas cosas hoy, sino plantearme la pregunta que estrictamente plante el título de este Simposio, pero como si tuviese un signo de interrogación: "Novela en español, ¿hoy?". Citaba yo a mi maestro Alfonso Reyes el otro día cuando me decía: "La literatura mexicana será buena por ser literatura y no por ser mexicana". Creo que esto es válido para la novela en lengua española, hoy. La literatura en lengua española será buena por ser literatura y no por ser en lengua española estrictamente, ni por ser peruana, o mexicana, o española. Las diferencias entre la literatura que se escribe en español y la que se escribe en otras lenguas esencialmente no son demasiado grandes. Todos nos enfrentamos a los mismos problemas, que son los de la supervivencia misma, de la palabra como medio de comunicación, como medio de recreación, como medio de volar, como dijo William Gass esta mañana, de renacer a través de la palabra.

Mi más estrecha relación con España, puesto que es la pregunta que me hace José Miguel Oviedo, tiene que ver, claro, con cierto hecho que para mí marca el nacimiento del mundo moderno. cuando se me pregunta en las clases de historia, a las que todavía asisto, cuándo empezó la edad moderna, yo nunca contesto con el descubrimiento de América, o con la publicación de los libros de Copérnico, o con la caída de Constantinopla en manos de los turcos. No. Nació en 1605, cuando un hidalgo de La Mancha salió a recorrer la tierra. Salió de sí mismo, y salió a conocer al mundo, y a través del conocimiento del mundo, se conoció realmente a sí mismo, y aprendió a poner en duda y a criticar al mundo, a crear este instrumento maravilloso, insustituible, de desajenación, de conocimiento a través de la imaginación, que llamamos la novela. Toda novela, yo creo, por fuerza, nace de la historia, tiene su sede en la historia, pero al mismo tiempo la trasciende. Es el instrumento que nos permite salir de la historia para verla, a fin de no ser esclavos de ella. En este sentido creo que la novela es un instrumento precioso de libertad. Es un instrumento que nos permite imaginar y dirigir nuestra propia historia. Y es, finalmente, un instrumento que nos permite moldear el tiempo humano, crear 
el tiempo que requerimos, que cada una de nuestras sucesivas generaciones requiere y que nuestras culturas, en un mundo policultural como el que estamos viviendo, requieren. Creo que estas grandes exigencias de la forma novelesca, de las que estoy hablando, se imponen a todos nosotros a los que escribimos en español, pero, repito, no son distintas de las exigencias a las que se enfrenta Italo Calvino, o Milán Kundera, o Kuznievitz, o Georg Konrad en Hungría, o Günter Grass, o William Golding, o William Styron, o Paul West, o William Gass. Simplemente, lo que yo quisiera decir realmente es que siendo el mundo narrativo tan ancho y tan frágil al mismo tiempo, lo último que debemos hacer es crear barreras artificiales dentro de una propia lengua, la lengua castellana. Yo no admito la división entre literatura peruana, argentina, cubana, mexicana, o española. No admito la división del Atlántico. Yo creo que Goytisolo, por ejemplo, pertenece a la misma empresa que nosotros, no porque él se volvió latinoamericano, ni porque nosotros nos volvimos españoles, sino porque estamos en una misma empresa de la imaginación y del lenguaje.

Déjenme nada más para terminar decirles que he tenido una experiencia muy curiosa este verano, y es la de haber escrito por primera vez una novela en inglés, una novela breve en lengua inglesa, para ver qué se siente ser Conrad ¿verdad? Pero he sufrido enormemente y por un hecho muy claro. Me sentí vigilado constantemente mientras escribía en inglés. Sentí que había una serie de fantasmas que aparecían por las ventanas, que asomaban por los closets, debajo de las camas, me hacían caras. “Cómo te atreves a escribir eso?”, me decía Faulkner, y Hawthorne me decía: "No, no, no, no, eso no". Y Herman Melville me echaba un arponazo digno del capitán Acab y salía George Eliot (la mujer) y me decía otras cosas. Y me sentía yo sumamente incómodo y sin la libertad a la que estoy acostumbrado en lengua española. Yo creo que sencillamente se escribe en la lengua en la que se sueña y en la que se hace el amor, y se juramenta, ¿verdad? Yo nunca me siento insultado por una injuria en lengua inglesa o francesa. Si alguien me dice "Fils de chameau": me quedo igual. "Mother fucker": no me importa. Pero me dicen "Hijo de la chinga da", y me indigno. Pero hay algo más: escribiendo en español, tengo la sensacióny creo que en esto estaríamos todos de acuerdo-de pertenecer a una tradición muy poderosa, pero, además, de hacer desafíos dentro de esa tradición, de decir cosas no dichas, de llenar vastas lagunas históricas, de dar saltos de siglos para volver a darle la mano a Quevedo, para volver a darle la mano a los autores de las novelas de caballerías, para volver a darle la mano al Arcipreste de Hita, porque no tenemos esa continuidad de la lengua inglesa, porque en la lengua española hay la posibilidad de esta maravillosa aventura, que es la que ilumina nuestras imaginaciones. 
JORGE EDWARDS: Lo que contó Juan Goytisolo me hizo recordar la anécdota de un poeta chileno, que quizá conozcan: Enrique Lihn, hace muchos años en París. Enrique Lihn había aterrizado en París en unas condiciones económicas desastrosas, prácticamente se moría de hambre. Yo le había dado alojamiento en mi casa en ese tiempo. Y un día apareció en mi casa un profesor norteamericano, de una universidad que no recuerdo dónde quedaba, que se había dedicado durante los dos últimos años a estudiar los adjetivos de la poesía de Enrique Lihn, y que se ganaba la vida, digamos, estudiando los adjetivos en su poesía. Y yo le dije a Lihn que eso me recordaba un dicho chileno popular que dice así: "Todos piden naranjada, y al naranjo nada". Y lo que acaba de decir Carlos me recuerda una anécdota un poquito más triste. Cuando yo tenía veinte años, publiqué mi primer libro, un libro de cuentos que se llamaba El patio, y por ese motivo mis amigos me llevaron a un bar del centro de Santiago. Y en ese bar apareció un personaje completa mente desharrapado, en un lamentable estado de conservación física, pero que tenía una cantidad de lápices de marca Faber en el bolsillo. Sacó un lápiz, me lo regaló, y me dijo: "Al talento se lo premia con un lápiz". Y este personaje era un escritor chileno en decadencia, pero que había estado ligado al movimiento surrealista chileno, había pertenecido a un grupo que se lla maba Mandrágora, el grupo surrealista chileno de los años 30 . Se había escrito su propio epitafio, que fue quizá su última obra. El epitafio decía así: "Quiso ser escritor, y sólo llegó a ser escritor chileno".

Esta relación del mundo de la literatura de España, digamos, con la literatura nuestra y con nuestro oficio, es un tema que me ha interesado y me ha preocupado desde que comencé a escribir, desde mis catorce años de edad. Yo sólo quiero contar un par de pequeñas anécdotas que tienen relación con mi trabajo personal en este aspecto. Por ejemplo, quiero decir que leí casi por azar, hace dos o tres años, un poema popular chileno y ese poema popular no sólo me dio la idea del título de mi última novela, Los convidados de piedra, sino que me hizo pensar en la forma muy extraña como el tiempo español se prolonga en América Latina; como, por ejemplo, la Edad Media termina en España pero continúa inmovilizada de alguna manera en cierta parte del mundo latinoamericano. Es un poema que en realidad cuenta la historia del convidado de piedra. Habla de un hombre joven, presumido, y algo donjuanesco, que va a misa y el poema dice: "Pero no va a misa por oír misa, sino que pa'ver las damas"-porque el poema sigue la fonética chilena. Y cuando va entrando en una gran iglesia se encuentra con una calavera que está en el suelo y le da una patada. Y entonces la calavera rueda y al chocar contra un muro, la calavera increpa al joven, le dice que es un insolente, que se fije mejor en lo que hace, y lo invita a cenar. Pero el poema termina bien, a diferencia del Convidado de piedra de Tirso, porque la calavera perdona al 
joven. Al fin y al cabo el joven no había asesinado a nadie, y era más inocentón que el personaje de Tirso. Y este tema justamente me dio la idea del título y en cierto modo incluso la idea total de esa novela, en la que un grupo de jóvenes petulantes y presumidos están bebiendo champán para celebrar el golpe de estado que ha derribado del poder a Salvador Allende. O sea, están bebiendo para celebrar una muerte. Y a través de la conversación de estos jóvenes, surgen precisamente las voces de los convidados de piedra, voces que hacen un llamado a la conciencia, con la historia de los marginados, de los suicidas, de los exilados, de los torturados. Es la gente que se separó del grupo no sólo por razones políticas sino por razones morales, incluso por debilidades humanas

Yo pensé también, cuando me planteó José Miguel este tema, que Chile quizá es, por excelencia, un país de América Latina que ha sido inventado por un escritor, por un poeta español. Porque, como ustedes saben, don Alonso de Ercilla, que estaba en la corte de Inglaterra, durante las bodas de Felipe II, escuchó que había un lugar en el imperio español donde se podía conquistar gloria, como en las novelas de caballerías, porque era el lugar donde los indios, los nativos, estaban resistiendo con gran fiereza, y donde por consiguiente se podían ganar batallas en una verdadera acción de caballero andante. Y Ercilla parte a Chile, termina en el sur del país, participa en la guerra de la Araucanía y escribe La Araucana, que en cierto modo es una invención, una creación legendaria sobre los indios de la Araucanía, porque éstos son comparad os con los héroes de la antigüedad clásica, se les atribuyen cualidades guerreras absolutamente exageradas y fantásticas. A partir de ese poema, empieza a desarrollarse un sentido nacional en Chile bastante fuerte. O sea que Chile, en cierto modo, es un país inventado por don Alonso de Ercilla, es una invención poética. Quizás por eso se ha dicho que Chile es un país de poetas. Ahora, ese contraste de tiempos es un contraste que se da en toda la literatura latinoamericana y que en algunos casos se da de una manera más consciente, más deliberada y lúcida; por ejemplo, en la obra de Alejo Carpentier, donde el tema del encuentro de dos tiempos históricos es obsesivo y que aparece desde sus orígenes.

Mi última novela, por ejemplo, mi novela todavía inédita, que se llama $E l$ museo de cera, tiene mucho que ver con lo español y con lo sudamericano, porque es una historia que yo leí en una vieja crónica chilena, pero que se refiere a un suceso ocurrido en el Madrid de fines del XIX. Es una historia que, para mí, tiene mucho que ver con el tiempo-lo que me permitió hacer una especie de reflexión y de juego con el tiempo en la novela-porque es la historia de un marqués muy rico, que tenía una mansión muy opulenta en el centro de Madrid, pero que llevaba una vida muy rutinaria, muy metódica. Estaba casado con una mujer muy joven y muy bella y que hacía clases de piano todas las tardes después de la hora de comer. Y este marqués todas las 
tardes iba a su club donde jugaba al bacarat. Y un buen día, el marqués, por un asunto trivial que rompió la rutina de sus días, regresó a su casa, entró a la sala del piano y encontró a su mujer haciendo el amor con el profesor, un pia nista italiano. Esto para mí es sólo el comienzo de la novela, porque lo que después hizo ese marqués-que me pareció algo muy sorprendente, y que es, en realidad, un intento de detener el tiempo, una especie de rebelión frente a esta ruptura de la rutina que se había producido en su vida - fue encargarle a un escultor que le hiciera unos muñecos de cera que representaran exactamente a la mujer y al pianista en la posición en que estaban cuando él abrió esa puerta. Mi novela comienza cuando el marqués contrata el trabajo con el escultor, empieza a explicarle la forma en que descubrió a su mujer, a exigirle que el color del muslo de la mujer en contraste contra la caoba negra del piano se dé con la exactitud, con la palidez, con el color violáceo preciso que a él le interesa. Y pide además - en mi novela, no sé si lo pidió así en la realidad-a ese escultor, que además de colocar a los dos personajes, lo coloque a él, el voyeur, en el momento de abrir esa puerta. O sea, esa sala pasa a ser un lugar donde el tiempo está detenido. Y la próxima empresa del marqués es cerrar esa casa, y en mi novela no es Madrid sino que es una ciudad colonial sudamericana, donde hay un mundo de desharrapados, confuso y caótico, que coexisten con ciertos elementos ultramodernos del mundo electrónico de hoy, digamos. En ese aspecto yo creo que quizás, sin quererlo - porque yo no me propuse en absoluto hacer alusión a la realidad política chilena-aludía a la situación chilena, porque el régimen actual habla con gran insistencia de las modernizaciones que hace Pinochet en la vida chilena, en alianza con los Chicago boys, que son los alumnos de Milton Friedman que manejan actualmente la economía nacional. En el Chile de hoy, hay una simbiosis extrañísima de caudillismo latinoamericano del siglo XIX representado por el general Pinochet, con toda su parafernalia, con sus charreteras y sus capas. Algunos amigos españoles, cuand o lo veían en la televisión en España, decían que parecía el Prisionero de Zenda. Todo este mund o anacrónico, combinado con un mundo de banqueros jóvenes, sumamente modernos en realidadporque hoy día un banco en Chile no es como los de hace diez años-rodeados de computadoras, de a paratos electrónicos, en conexión de telex con Tokio y con Nueva York y con Hong Kong. Es una combinación alucinante de tiempos, que mezcla el mundo del pasado con el mundo del futuro en un país subdesarrollado. Que haya barrios en Santiago que parecen realmente barrios de una ciudad norteamericana más o menos desarrollada, y que a cinco kilómetros de allí se viva, no diré en la edad de piedra, pero sí en un comienzo de siglo muy miserable, toda esta fusión de tiempos a mí me parece un tema de reflexión muy sugestivo. Y creo que forma parte de esa relación histórica del mundo literario español e hispanoamericano, que se considera en esta mesa. 
MARIO VARGAS LLOSA: Bueno, acatando la sugerencia de José Miguel Oviedo, les voy a hablar un poco sobre mi afición por las novelas de caballerías, afición que, como ustedes saben, volvió loco al Quijote. Espero que no me haya ocurrido lo mismo. Creo que es un testimonio que puede ser revelador de lo que ocurría en el Perú y probablemente en otros países latinoamericanos hace veinticinco o treinta años, con la enseñanza de la literatura española o la enseñanza de la cultura española, en Hispanoamérica. Creo que mi generación literaria fue mucho más influida por otras culturas que por la española. Hablo de la que se formó en la Universidad en los 50. Había una resistencia muy fuerte hacia todo lo que venía de España. Creo que es una resistencia motivada en parte por el fenómeno del franquismo. Todo lo que venía de España absurdamente lo asociábamos con Franco, con un régimen que había provocado tanta repugnancia en América Latina, sobre todo en el medio intelectual, y quizás porque esta cultura nos llegaba filtrada, organizada, publicitada, por los hispanistas nativos. $\mathrm{Y}$ el hispanismo representaba, por lo menos en el caso del Perú, algo que era muy poco estimulante desde el punto de vista intelectual, político e incluso moral. Representaba una forma sumamente reaccionaria de visión de la historia y de la cultura. las cátedras de literatura y cultura españolas en las universidades estaban controladas por los hispanistas, generalmente señores ultramontanos y profundamente académicos, y el tipo de información que nos llegaba a través de ellos, por ser una informacion muy poco estimulante desde el punto de vista literario, para un joven que descubría la literatura y la vocación de escritor. Mi primera reacción al entrar en la universidad frente a los cursos de literatura española, fue una reacción de hostilidad, cuando no de simple indiferencia.

Descubrí la novela de caballerías por espíritu de contradicción. Uno de los profesores que tenía en mi primer año de Universidad, el año. '53, en San Marcos, en Lima, dedicó en una de las clases unas cuantas frases a la novela de caballerías, para liquidarla rá pidamente con unos adjetivos denigrantes. Dijo, repitiendo lo que en realidad han dicho muchas historias de la literatura española, que la novela de caballerías representaba una forma sumamente primitiva, deshilvanada, absurda, del género y que incluso algunas de las novelas de caballerías, además de ser amorfas, caóticas, confusas, podían ser también soeces, y hasta sicalípticas... Yo creo que eso de soeces y sicalípticas encendió mi curiosidad y mi imaginación y me llevó a la biblioteca de la Universidad de San Marcos a buscar alguna novela de caballerías a ver si era cierto que las novelas de caballerías eran lo que decían. Tuve la suerte de que cayera en mis manos una novela de caballerías que es, dentro del género, algo extraordinario, que estaba escrita no en español sino en catalán-valenciano: hablo de Tirant lo Blanc-Tirante el Blanco. Es una novela mencionada por 
Cervantes en el Quijote de una manera ambigua, porque en un momento se dice de Tirante el Blanco que es éste el mejor libro del mundo, y en otro momento merece una frase más bien irónica. Comencé a leer este libro con bastante dificultad porque su lenguaje no me era familiar en absoluto. Pero a pesar de esta dificultad lingüística, fui inmediatamente seducido, vampirizado, canibalizado por la fuerza de la historia, la fuerza narrativa del libro. La leí con verdadera voracidad, y creo que así contraje la adicción del género. Después, en el resto de mis a ños universitarios, seguí leyendo novelas de caballerías, algunas con más dificultad que otras, ninguna con el entusiasmo con que había leído Tirante el Blanco, aunque algunas de ellas, como el Amadís, por ejemplo, me admiraron. Así llegué a la conclusión de que ese género había sido injustamente calumniado y desdeñado por escritores y críticos de nuestra lengua. Pues se trataba de un género de una enorme riqueza, de una enorme vitalidad, y sobre todo con un extraordinario caudal de enseñanzas para un escritor o un lector moderno de literatura.

Me he preguntado años después, qué es lo que hizo que me entusiasmase de este modo con ese género que Cervantes mató de ridículo, según los críticos. Creo que las explicaciones son probablemente de dos órdenes. En la novela de caballerías española, descubrí algo que estaba íntimamente ligado con lo que había sido mi primer descubrimiento de la literatura; es decir, las novelas de aventuras que leí de niño. Yo descubrí la literatura como supongo la mayor parte du ustedes, leyendo novelas de aventuras, leyendo a Salgari, leyendo a Karl May, leyendo a Julio Verne, y sobre todo al primer gran autor que descubrí, que amé enormemente, y que sigo queriendo muchísimo, que es Alejandro Dumas. Generalmente la literatura se descubre de niño en novelas de avent uras de este tipo, y después esa experiencia se olvida, se supera, uno la trasciende y descubre una literatura más rica, más profunda, más compleja. Bueno, creo que también eso me pasó a mí, pero sin embargo nunca rechacé ese amor de infancia y creo que he vivido hasta ahora con un gran nostalgia por esas primeras manifestaciones de la literatura que conocí. Es decir, el mundo de la aventura, el mundo de proezas extraordinarias, de personajes justicieros, ese mundo en el que todo parece posible, en el que realmente la imaginación tiene plenos poderes para decidir la historia de las sociedades y de los individuos, que es el mundo de la novela de aventuras. Bueno, pues aquí, adulto, descubro de pronto que en mi propia tradición, es decir, en la tradición de las literaturas hispánicas, había una veta riquísima de una literatura de esta índole y que al mismo tiempo, podía ser leída por adultos y por niños. Creo que la literatura caballeresca es exactamente eso, es una visión del mundo aventurera, semejante a la que proponen los libros infantiles de aventuras, pero con una complejidad muchísimo mayor, aunque con una libertad parecida. Creo que ésta fue una de las razones por las cuales esta 
tradición me sedujo de esa manera, y despertó mi entusiasmo, mi interés por ella.

Ahora, creo que hay otras razones que son menos subjetivas, más defendibles en un plano general. Creo que este género ha sido efectivamente calumniado, ha sido malentendido por los profesores de literatura hispánica, porque en este género que efectivamente es primitivo y deshilvanado-las novelas suelen ser muchas veces enormes, de una prolijidad que muchas veces asfixia al lector-hay, sin embargo, una serie de elementos que están hoy presentes en la literatura moderna y que son considerados justamente definitorios de la modernidad. La novela es moderna porque tiene una libertad formal y una libertad de imaginación que no tenía la novela del siglo XIX, por ejemplo. En el caso de nuestra tradición, la tradición hispánica, esto es flagrante. A partir del Quijote, a partir de esa novela que mata de ridículo justamente a los libros de imaginación disparatada, o sea las novelas de caballerías, se establece una tradición de racionalismo y de realismo narrativos que lleva a pensar mecánicamente que la novela en nuestra lengua ha sido siempre eso: una novela realista y racionalista que pretende realmente re-escribir, relatar la realidad que conocemos a través de nuestra razón y de nuestra experiencia. Eso no es exacto, porque existe esta novela precervantina, que es una tradición numerosa, numerosa por la cantidad de novelas que se escribieron, y numerosa, internamente, por la cantidad de personajes u ocurrencias, niveles de realidad, que cada una de estas novelas suele retratar. En esta tradición no existe ninguna hegemonía racionalista, ni este exclusivo afán realista, que tendría la novela en español luego de Cervantes. Todo lo contrario. Lo que primero nos sorprende en una novela como Tirante el Blanco o en el Amadís, o incluso en novelas anteriores, como el Caballero Cifar, es la extraordinaria libertad de concepción, el tipo de realidad que este mundo literario describe. Lo que describe es por lo general una realidad que es múltiple, en verdad un abanico de realidades o una realidad compuesta de niveles muy distintos, en los cuales coexisten la razón y la sinrazón, una realidad objetiva y una realidad puramente subjetiva, una realidad hecha de experiencias y una realidad hecha de sueños, de pura fantasía, de milagros. Creo que en ninguna novela se consigue esto de una manera tan eficaz como en Tirante el Blanco.

¿Qué cosa es Tirante el Blanco? Tirante el Blanco puede ser muchas cosas a la vez y muchas cosas distintas e, incluso para la visión racionalista de la literatura, inconciliables. Puede ser una novela militar o puede ser una novela épica que describe las hazañas de un héroe justiciero, y al mismo tiempo puede ser una novela de la intimidad, una novela de la subjetividad. Hay una matización psicológica, por ejemplo, en los personajes, que es insólito, es verdad, en las novelas caballerescas. Pero es que Tirante el Blanco puede ser 
extraordinariamente sutil. Descubrimos ahí incluso una realidad subconsciente avant la lettre, porque vemos cómo a través de los sueños de ciertos personajes, ciertas conductas están determinadas oscuramente por ciertos impulsos o apetitos de infancia. También podría ser Tirante el Blanco una novela erótica porque efectivamente en esta novela hay procacidades y episodios sicalípticos, a veces sumamente subidos de color. Hay una libertad en la descripción de la conducta erótica de los personajes, que es extraordinaria, muy sorprendente, justamente dentro de lo que sería más tarde una tradición muy represiva en este campo.

Y al mismo tiempo hay, en Tirante y en la mayor parte de las novelas de caballerías, algo que a mí me parece, por una parte constitutivo del género y por otra parte lo que ha dado al género sus más altas creaciones, algo que podríamos llamar la ambición totalizadora. Creo que en la novela, a diferencia de lo que ocurre con otros géneros, el número, la cantidad, es un ingrediente fundamental de la calidad. Las novelas grandes no sólo son grandes cualitativamente, lo son también cuantitativamente porque pretenden abarcar materialmente muchos aspectos de la realidad, Esto lo vemos también de una manera flagrante en las novelas de caballerías que pretenden decirlo todo, contarlo todo, y que no quieren acabar nunca. Las novelas de caballerías se acaban casi por casualidad. Son novelas realmente interminables interminables por su discurrir en el tiempo pero también por su proyección en el espacio, por la manera cómo se extienden, por la manera cómo se proyectan en todos los niveles. Eso me parece algo sumamente indicativo de lo que es la apropiación novelesca de la realidad, de lo que es la creación novelesca. Creo que estos viejos antecesores nuestros, anónimos muchos de ellos, desdeñados por la cultura oficial de su tiempo y también por la cultura oficial posterior, pero que en su época fueron profundamente populares-puesto que esta novela tuvo una audiencia extraordinaria-creo que fijaron realmente lo que son los patrones de la narrativa. La novela moderna ha demostrado que la narración es fundamentalmente libre y que esa ambición totalizadora le permite proyectarse en todos los campos, en todos los terrenos e intentarlo todo en el dominio de la experimentación. Creo que un novelista tiene, en este sentido, mucho que aprender de la novela de caballerías, porque todo lo que él busca está ahí en embrión. Ésa es la otra razón por la cual el descubrimiento de este género fue para mí no sólo una gran experiencia como lector, sino también algo extraordinariamente útil en mi propio trabajo de escritor. Creo que estos viejos modelos de alguna manera me han servido, en las novelas que he escrito, como paradigmas. Y por eso estoy tan reconocido a ese género. Es quizás, por lo menos conscientemente, la mayor deuda que yo tengo con la tradición clásica de mi lengua. 
JOSÉ MIGUEL OVIEDO: Creo que con estas intervenciones, tan variadas y distintas entre sí pero todas con una intención de testimonio personal provocado por el tema general del Simposio, podemos cerrar la mesa redonda y clausurar nuestra reunión. Éste es, pues, el momento de expresar nuestra gratitud a todos: en primer término a los novelistas aquí presentes; luego a los ponentes de las diferentes mesas; y en general a todo el público, profesores y alumnos de casa, etc., que nos han acompañado a lo largo de estas jornadas. Si el Simposio ha tenido éxito es especialmente debido a la presencia y la participación intelectual de todos ustedes. Gracias.

CARLOS FUENTES: Yo creo que los cuatro que estamos presentes en la mesa y ustedes como público, no podemos irnos y levantar esta sesión sin expresar nuestra gratitud y reconocimiento a José Miguel Oviedo. Si estamos aquí es por él, por la amistad, el respeto que nos inspira y sobre todo por su infinita capacidad de persuasión. 
